\title{
Joe Stratford (1923-2007)
}

Joe Stratford was born September 5, 1923 and died July 22, 2007 of complications of chronic lymphocytic leukaemia.

Joe Stratford grew up in Brantford, Ontario and, in the 1940's, began an association with McGill University which was to last more than 60 years. Graduating from medical school in 1947, he then trained in neurosurgery with Wilder Penfield, William Cone, Arthur Elvidge and Herbert Jasper at the Montreal Neurological Institute. A supplemental period of training in general surgery was undertaken in London, England. Late in his residency he married Aurelie Forbes who was then secretary to Dr. Penfield.

On completion of his residency he served for a brief period as consultant neurosurgeon at the Montreal General Hospital and the Queen Mary Veteran's Hospital. In 1956, he moved to the University of Saskatchewan to join the fledgling unit in neurology and neurosurgery being created by Bill Feindel and Allan Bailey. Joe, together with Don Baxter and Jerzy Olszewski, saw this academic unit expand and flourish over the next six years. Unfortunately serious medical controversies followed proposals by the provincial government to introduce a universal health care program. These led to the resignation of the dean of medicine and the defection of many full-time specialists to other provinces.

The academic unit of neurology and neurosurgery was not immune to these developments. By the summer of 1962 several of Joe's close colleagues had left for other centres and Joe was completing negotiations with Rocke Robertson to return to the Montreal General Hospital as neurosurgeon-in-chief.

He remained at the Montreal General for the rest of his career. Until the arrival of Bob Ford in 1965, he was always on call at the hospital, gaining respite only through occasional crosscoverage with John Blundell at the Montreal Children's Hospital. Later recruitments of Peter Richardson and Jean-Louis Caron brought the number of neurosurgeons to four. Of necessity, a versatile neurosurgeon, Joe retained from his training with William Cone a particular affinity for surgery of the spine, especially the cervical spine. Residents on the service, whether destined for careers in neurosurgery or in other surgical specialities, recognised Joe for his courtesy, his calm under pressure in the operating room, and his teaching of clinical judgement. The nurses appreciated his patience and insight into non-surgical aspects of clinical care. He was chief of the neurosurgery service at the Montreal General Hospital for 30 years overseeing its development with foresight and equanimity.

Together with Don Baxter whom he repatriated to Canada and the Montreal General Hospital, Joe fostered a cordial and prosperous academic environment in neurosurgery and neurology. He enthusiastically encouraged Peter Richardson in the development of a basic science research programme. With other surgeons in the hospital, he collaborated in two major multidisciplinary trauma ventures, an idea before its time in the 1960's and a key programme of the hospital twenty years later. With Bob Ford and a devoted coterie of nurses, Joe established a closeknit neuro-intensive care unit on the 14th floor of the hospital. He started a multidisciplinary pain clinic in the 1970's, continued his work in pain even after withdrawing from clinical neurosurgery, and, with Alan Edwards, worked towards development of what is now the McGill Pain Centre.

At McGill, Joe served as a member of the Senate and, subsequently, was called upon to mediate in troublesome academic situations. After he eventually retired, he was asked to write a history of neurosurgery at McGill. At national level, he was president of the Canadian Neurosurgical Society and a member of the board of directors of the Victorian Order of Nurses for many years.

A recital of professional accomplishments does not portray the respect that Joe Stratford commanded in the English Montreal community over decades. His awareness, judgement, and quiet eloquence made him a valued advisor for many. His life-long passion for the visual arts brought him much satisfaction. He helped to maintain the historically strong relationship between the community and McGill's hospitals.

After the death of Aurelie in 1983, Joe never remarried. He remained close to his daughter, Leslie, and son, Huntly, and maintained a group of fortunate friends. He had no enemies.

Donald Baxter, Montreal, Canada Peter Richardson, London, England 